\title{
Comparison of once- with twice-daily dosing of fluticasone propionate in mild and moderate asthma
}

Louis-Philippe Boulet MD ${ }^{1}$, Robert L Cowie MD², Roberto Dal Negro MD ${ }^{3}$, Wade Brett MD ${ }^{4}$, Milton Gold MD ${ }^{5}$, Agostinho Marques MD ${ }^{6}$, William S Thorburn MD ${ }^{7}$, Nate M Stepner D Litt ${ }^{8}$, Reid Robson M MATH ${ }^{9}$

${ }^{1}$ Institut de cardiologie et de pneumologie de l'Université Laval, Hôpital Laval, Sainte-Foy, Québec, ${ }^{2}$ University of Calgary, Calgary, Alberta, ${ }^{3}$ Servizio Di Fisiopatologia Respiratoria, Ospedale Civile, Bussolengo, Italy, ${ }^{4}$ Auckland, New Zealand, ${ }^{5}$ The Medical Place, Brampton, Ontario, ${ }^{6}$ Servico de Pneumolgia, Faculdade de Medicina do Porto, Hospital São João, Porto, Portugal, ${ }^{7}$ St Andrews Surgeries, Keighley, West Yorkshire, United Kingdom, ${ }^{8}$ Respiratory Research Group, Glaxo Wellcome Inc, ${ }^{9}$ Medical Data Sciences, Glaxo Wellcome Inc, Mississauga, Ontario

L-P Boulet, RL Cowie, R Dal Negro, et al. Comparison of once- with twice-daily dosing of fluticasone propionate in mild and moderate asthma. Can Respir J 2000;7(3):239247.

OBJECTIVES: Two 12-week, randomized, double-blind, parallel-group studies were performed to compare the efficacy and safety of once- and twice-daily dosing of fluticasone propionate (FP) in the treatment of mild to moderate asthma, considered to require the equivalent of either 200 or $500 \mu \mathrm{g}$ of FP daily.

PATIENTS AND METHODS: In study A, 461 patients with asthma received FP either $200 \mu \mathrm{g}$ once daily or $100 \mu \mathrm{g}$ twice daily. In study B, 443 patients with asthma received FP, either $500 \mu \mathrm{g}$ once daily or $250 \mu \mathrm{g}$ twice daily.

RESULTS: In both studies, regardless of the treatment regimen to which patients were randomly assigned, small improvements over baseline were observed in morning peak expiratory flows (PEF)and forced expiratory volume in $1 \mathrm{~s}$ $\left(\mathrm{FEV}_{1}\right)$ following 12 weeks of treatment. In study $\mathrm{A}$, the mean morning PEF improved by $2.4 \%$ and $4.3 \%$ (once daily versus twice daily, $\mathrm{P}=0.008$ ). In study $\mathrm{B}$, the mean morning
PEF improvement was $0.2 \%$ and $3.7 \%$ (once daily versus twice daily, $\mathrm{P}<0.001$ ). For both studies, the increases observed in $\mathrm{FEV}_{1}$ were not significantly different between the two groups $(\mathrm{P}=$ not significant). The incidence of exacerbations of asthma and related events was $13 \%$ and 5\%, respectively, in the patients with mild asthma for the once-daily group versus the twice-daily group; these exacerbations were $12 \%$ and $10 \%$, respectively, in patients with moderate asthma. Otherwise, the incidence and types of adverse events were comparable for the two treatment regimens. Although twice-daily dosing demonstrated small but statistically significant improvements over once-daily dosing, patients of both groups generally maintained a good level of asthma control on both regimens according to current treatment guidelines.

CONCLUSIONS: Twice-daily dosing of FP is more effective than once-daily dosing, although the latter can maintain asthma control in most patients.

Key Words: Asthma; Dosing frequency; Fluticasone propionate; Inhaled corticosteroids; Once daily; Twice daily

Pour le résumé, voir page suivante 


\section{Comparaison de l'administration die versus b.i.d. du propionate de fluticasone dans l'asthme léger et modéré}

OBJECTIF : Deux études randomisées à double insu avec groupe parallèle d'une durée de 12 semaines ont été effectuées dans le but de comparer l'efficacité et l'innocuité d'une administration die versus b.i.d. du propionate de fluticasone (PF) dans le traitement d'un asthme léger à modéré nécessitant respectivement l'équivalent de soit 200 ou $500 \mu \mathrm{g}$ de PF par jour.

PATIENTS ET MÉTHODES : Dans l'étude A, 461 patients asthmatiques ont reçu du PF à raison de $200 \mu \mathrm{g}$, die ou de $100 \mu \mathrm{g}$, b.i.d. Dans l'étude B, 443 patients asthmatiques ont reçu du PF à raison de $500 \mu \mathrm{g}$, die ou de $250 \mu \mathrm{g}$, b.i.d.

RÉSULTATS : Dans les deux études, peu importe le groupe, on a observé de légères améliorations par rapport aux valeurs initiales dans les débits expiratoires de pointe (DEP) du matin, après 12 semaines de traitement. Dans l'étude A, le DEP moyen du matin s'est amélioré de $2,4 \%$ et de 4,3\% (die versus b.i.d., $\mathrm{p}=0,008$ ). Dans l'étude B, l'amélioration moyenne du DEP du matin a été de $0,2 \%$ et de $3.7 \%$ ( $\mathrm{p}<0,001)$. Pour les deux études, les changements $\mathrm{du}$ VEMS des deux groupes étaient similaires $(\mathrm{p}=\mathrm{NS})$. L'incidence des exacerbations de l'asthme a été de $13 \%$ et de $5 \%$ respectivement chez les patients atteints d'asthme léger, dans le groupe traité die versus b.i.d. Ces exacerbations étaient de 12 et $10 \%$ respectivement chez les patients atteints d'asthme modéré. L'incidence et les types de réactions indésirables ont été comparables pour les deux types de traitement. Bien que le schéma b.i.d. ait donné lieu à des améliorations légères, mais statistiquement significatives, par rapport à l'administration die, surtout chez les patients atteints d'un asthme plus prononcé, les sujets des deux groupes ont en général maintenu une maîtrise adéquate de leur asthme avec les deux types de traitement administrés, tel que défini par les récents guides thérapeutiques.

CONCLUSION : Le PF est plus efficace s'il est administré b.i.d. plutôt que die, bien que l'administration uniquotidienne permet de maintenir une maîtrise adéquate de l'asthme chez les plupart des patients.
$\mathrm{I}_{\mathrm{p}}^{\mathrm{n}}$ nflammation is an important feature of the airways of patients with asthma, and inhaled corticosteroids (ICS) are recommended for patients who require regular use of an inhaled beta2-agonist to control asthma symptoms $(1,2)$. However, patient compliance with preventive therapy is often poor, particularly in a long term illness such as asthma, thus compromising the effectiveness of treatment $(3,4)$. One method of improving compliance is to simplify the dosing regimen by decreasing the number of times that the medication has to be taken each day. Improvements in compliance have been achieved by reducing dosing frequency from four times per day to twice per day, and further improvements in compliance may be achieved with once-daily dosing $(5,6)$.

The evidence as to whether equivalent dosages of ICS given once- or twice-daily are equally effective is conflicting. Several studies of patients with stable asthma have found that once-daily ICS was as effective as half the dose given twice daily (7-13). However, two studies have reported the twice-daily administration of ICS to be more effective in the control of asthma than once-daily administration $(14,15)$, and Weiner et al (16) found that, over 12 months, better control was achieved using twice-daily than with once-daily therapy. The timing of the once-daily dose of ICS was thought to be important; afternoon or evening dosings were equally as effective as twice-daily dosing and more effective than morning dosing $(9,12)$. This supports the concept that circadian rythms influence the manifestations of asthma and the response of asthma to therapy (17).

Although the administration of ICS at the end of the day may better antagonize an increased airway responsiveness and inflammation occuring at night, it is not known whether a morning dosage may be sufficient to control asthma with a potent ICS while possibly further reducing the risk of systemic side effects.

Fluticasone propionate (FP) is a topically active, synthetic glucocorticosteroid that is usually prescribed twice daily for the treatment of asthma. The safety and efficacy of FP in a twice-daily dosing regimen have been established in numerous clinical trials (18-24). FP may be a suitable drug for once-daily dosing because it is highly lipophilic; lipophilicity is an important property for an ICS because it increases both drug uptake and retention in tissues, thereby prolonging the duration of action (25). The present study aimed to compare the clinical efficacy of FP administered in once-daily with that of twice-daily dosing regimens, and to examine their safety.

\section{PATIENTS AND METHODS}

Study design and treatment regimen: Two separate, multicentre, randomized, double-blind, parallel-group studies examined the efficacy and safety of FP given once or twice daily in patients with mild (study A) or moderate (study B) asthma. The study protocols were approved by local ethics committees at each participating centre, and the patient's informed consent was obtained before being included in a study. The designs of the studies were identical. After a two-week run-in during which patients continued to take their usual asthma medication, patients entered a 12week, double-blind treatment phase. All patients were required to stop their prestudy ICS medication at this time. In study A, patients with mild asthma were randomly assigned to receive either once-daily treatment $(200 \mu \mathrm{g} \mathrm{FP}$ in the morning and placebo in the evening) or twice-daily treatment (100 $\mu \mathrm{g}$ FP in the morning and $100 \mu \mathrm{g}$ FP in the evening). In study B, patients with moderate asthma received once-daily treatment $(500 \mu \mathrm{g}$ FP in the morning and placebo in the evening) or twice-daily treatment ( $250 \mu \mathrm{g}$ in the morning and 250 $\mu \mathrm{g}$ in the evening). All patients attended the clinic on five occasions during the treatment period and two weeks after the completion of study treatment. 
Salbutamol was provided as relief medication during both run-in and treatment periods. Providing that the route, dose and frequency remained constant, the following asthma medications were permitted during the study: sodium cromoglycate, nedocromil sodium, ketotifen, methylxanthines, inhaled anticholinergics, long acting beta2-agonists and oral beta2-agonists. Intranasal corticosteroids for rhinitis, antifungal medication for oropharyngeal candidiasis and medications for other disorders, with the exception of systemic corticosteroids, were also permitted.

Patients were aged 12 years and over with a clinical history of mild (study A) or moderate (study B) asthma, as defined in the 1992 International Consensus Report on Diagnosis and Treatment of Asthma (26), for at least the preceding 12 weeks. Study A patients had a forced expiratory volume in $1 \mathrm{~s}\left(\mathrm{FEV}_{1}\right)$ between $70 \%$ and $90 \%$ of predicted normal values and had previously received no ICS or up to $500 \mu \mathrm{g} /$ day beclomethasone dipropionate (BDP), budesonide (BUD) or flunisolide, or up to $200 \mu \mathrm{g} /$ day FP. Study B patients had an $\mathrm{FEV}_{1}$ between $60 \%$ and $90 \%$ that of the predicted normal value and had previously received at least $400 \mu \mathrm{g} /$ day and up to $1200 \mu \mathrm{g} /$ day BDP, BUD or flunisolide $(600 \mu \mathrm{g} /$ day of FP). All patients were required to have no changes in their asthma medication during the preceding four weeks, at least $15 \%$ reversibility of their $\mathrm{FEV}_{1}$ 15 mins after inhaling salbutamol (200 $\mu \mathrm{g}$ via a metered dose inhaler or $400 \mu \mathrm{g}$ via Diskhaler) and the ability to withhold an inhaled short acting bronchodilator for a minimum of $4 \mathrm{~h}$ before each clinic visit. Patients were excluded if their asthma was unstable or they had recently received any corticosteroids other than by inhalation; they had had a respiratory tract infection or had required emergency room treatment in the preceding four weeks; they had a concurrent disease likely to interfere with the study; they had a history of hypersensitivity to ICS; or they were unable to use salbutamol on an 'as required' basis. Pregnant or lactating women were also excluded.

Efficacy assessments: The primary efficacy parameter was morning peak expiratory flow (PEF), measured daily through weeks 1 to 12 , with secondary variables being evening PEF, diurnal variation in PEF, percentage predicted morning and evening PEF, day- and night-time asthma symptom scores, number of days with total symptom score of less than 2 , symptomatic bronchodilator use and lung function measurements taken at the clinic (PEF and FEV $\mathrm{FV}_{1}$ ). PEF was measured using a mini-Wright peak flow meter. The best of three measurements was recorded in the diary card each morning and evening.

Symptom severity and bronchodilator use were recorded by the patients each day in a diary card. Daytime symptoms were rated on a scale of 0 to 5 , where $0=$ no symptoms and $5=$ symptoms so severe that the patient could not work or perform normal daily activities. Night-time symptoms were rated on a scale of 0 to 4 , where $0=$ no symptoms and $4=$ symptoms so severe that the patient did not sleep at all. Lung function measurements were performed at each of seven clinic visits (prestudy; end of run-in; after two, four, eight and 12 weeks of treatment; and after follow-up), and the highest of three PEF and $\mathrm{FEV}_{1}$ values was recorded. Patients were asked to withhold short acting beta2-agonists for $4 \mathrm{~h}$, long acting inhaled beta2-agonists for $12 \mathrm{~h}$ and oral beta2-agonists for $24 \mathrm{~h}$ before attending the clinic.

Safety assessments: All adverse events were recorded throughout the study and their relationship to treatment assessed. In addition, physical examinations, vital signs, routine urinalysis, hematology and biochemistry, including serum cortisol measurements as a measure of hypothalamicpituitary-adrenal axis function were conducted at baseline and repeated at the end of the study. Patients were required to attend the laboratory between 8:00 and 10:00 (time indicated in patients' charts) for the measurement of these parameters. Asthma exacerbations were defined as an increase in asthma symptoms requiring a change in bronchial anti-inflammatory treatment.

Data analysis: Data were analyzed using SAS ,version 6.08 (SAS Institute, Cary, North Carolina), on an intent-to-treat basis defined as all patients chosen randomly to receive treatment unless there was evidence that the study medication was not taken. For analysis, at least a baseline period measurement and one treatment period measurement were required.

All tests were carried out at the two-sided 5\% level of significance. An equivalence test was carried out for the primary efficacy variable (mean morning PEF for weeks one to 12 of treatment) by comparing the $90 \%$ confidence interval for the difference between two treatments with the predefined equivalence interval $(-15 \mathrm{~L} / \mathrm{min}, 15 \mathrm{~L} / \mathrm{min})$. Based on an estimated within-patient residual standard deviation of $40 \mathrm{~L} / \mathrm{min}$, 364 patients (assigned randomly in each study) were required to afford $95 \%$ power for declaring equivalence for the intentto-treat analysis with a type I error of 5\%.

Daily diary card data were summarized per patient by taking the mean over the treatment period for the following variables: morning and evening PEF; the diurnal variation in PEF (defined as the difference between the previous evening and next morning values); percentage predicted morning and evening PEF; and number of days with symptom scores of less than 2. An ANCOVA was performed on these variables using run-in baseline values as a covariate and adjusted for age, centre or country, and sex. An ANCOVA was also performed on the measurements of PEF and $\mathrm{FEV}_{1}$ taken in the clinic, using baseline values as covariates.

Secondary efficacy measures of asthma symptoms and use of relief medication were presented as frequency distributions and compared using the Wilcoxon rank-sum test. The Hodges-Lehmann estimate for the difference between treatment medians of median daytime score and corresponding $90 \%$ confidence limits were calculated.

All patients randomly assigned to treatment were included in the safety analysis. Treatment groups were compared with respect to all most common adverse events and all predictable adverse events using Fisher's exact test (two-sided). 
TABLE 1

Patient characteristics and their prestudy predicted morning peak expiratory flow (study A) or their prestudy inhaled corticosteroid dose (study B)

\begin{tabular}{|c|c|c|c|c|c|c|}
\hline \multirow[b]{2}{*}{ Dose regimen } & \multicolumn{3}{|c|}{ Study A - mild asthma } & \multicolumn{3}{|c|}{ Study B - moderate asthma } \\
\hline & $\begin{array}{c}200 \mu \mathrm{g} \\
\text { once daily }\end{array}$ & $\begin{array}{c}100 \mu \mathrm{g} \\
\text { twice daily }\end{array}$ & & & $\begin{array}{c}500 \mu \mathrm{g} \\
\text { once daily }\end{array}$ & $\begin{array}{c}250 \mu \mathrm{g} \\
\text { twice daily }\end{array}$ \\
\hline Male n (\%) & $106(46 \%)$ & $105(45 \%)$ & & & $99(45 \%)$ & 99 (45\%) \\
\hline Female n (\%) & $124(54 \%)$ & $126(55 \%)$ & & & $123(55 \%)$ & $122(55 \%)$ \\
\hline Age (years) & 37.0 & 38.0 & & & 36.0 & 36.7 \\
\hline <one $\mathrm{n}(\%)$ & $11(5 \%)$ & $7(3 \%)$ & & & $75(34 \%)$ & $92(42 \%)$ \\
\hline one to five $\mathrm{n}(\%)$ & $55(23 \%)$ & $70(31 \%)$ & & & $140(63 \%)$ & $128(58 \%)$ \\
\hline six to $10 \mathrm{n}(\%)$ & 50 (22\%) & $40(17 \%)$ & & & 0 & 0 \\
\hline$>10 \mathrm{n}(\%)$ & $114(50 \%)$ & $114(49 \%)$ & & & $7(3 \%)$ & $1(<1 \%)$ \\
\hline $90 \%$ to $100 \% \mathrm{n}(\%)$ & $58(34 \%)$ & $60(35 \%)$ & & & $57(27 \%)$ & $47(22 \%)$ \\
\hline$>100 \%$ n (\%) & 0 & 0 & & & $52(24 \%)$ & $53(25 \%)$ \\
\hline \multicolumn{7}{|c|}{ Prestudy inhaled corticosteroid dose $(\mu \mathrm{g} / \mathrm{day})^{*}$} \\
\hline prn to $300 \mathrm{n}(\%)$ & 28 (18\%) & $25(15 \%)$ & 400 & $\mathrm{n}(\%)$ & $39(18 \%)$ & $49(23 \%)$ \\
\hline$\leq 400 \mathrm{n}(\%)$ & $72(46 \%)$ & 75 (46\%) & $600-800$ & $\mathrm{n}(\%)$ & $49(23 \%)$ & $44(20 \%)$ \\
\hline$\leq 500 \mathrm{n}(\%)$ & $44(28 \%)$ & $53(33 \%)$ & 800 & n (\%) & 57 (26\%) & $47(22 \%)$ \\
\hline$>500$ n (\%) & $13(8 \%)$ & $10(6 \%)$ & $>1000$ & n (\%) & 72 (33\%) & 77 (35\%) \\
\hline
\end{tabular}

Numbers based on patients entered into the trial for all parameters, except for prestudy predicted morning peak expiratory flow and prestudy inhaled corticosteroid dose parameters, which are based on the evaluable population. *All types of corticosteroids included without correction for dosage equivalence. Prn As required

\section{RESULTS}

Study A enrolled 523 outpatients from 49 centres in eight countries. Of these, 461 patients were randomly assigned to treatment, 230 received FP $200 \mu \mathrm{g}$ once daily and 231 received FP $100 \mu \mathrm{g}$ twice daily. In study B, 507 outpatients were enrolled from 32 centres in Canada. Of these, 443 were randomly assigned to treatment -222 received FP $500 \mu \mathrm{g}$ once daily and 221 received FP $250 \mu \mathrm{g}$ twice daily. Because of a lack of adequate source data documentation, one centre in study B that had enrolled nine patients was excluded from the intent-to-treat population (434 patients, 217 in each treatment group). The two treatment groups in each study were comparable in terms of age, duration of asthma and other demographic variables (Table 1). In addition, the patients in the two treatment groups were balanced with respect to the degree of their asthma, as indicated by their prestudy predicted morning PEF, or their prestudy ICS dose (Table 1). Pulmonary function tests: For patients with mild asthma, study A, mean morning PEF improved over the 12-week treatment period in both treatment groups compared with baseline. Mean morning PEF increased by $10.5 \mathrm{~L} / \mathrm{min}$ with once-daily dosing, and $18.7 \mathrm{~L} / \mathrm{min}$ with twice-daily dosing (Table 2) - a statistically significant difference in favour of twice-daily dosing ( $\mathrm{P}=0.012)$. For patients with moder- ate asthma, study B, improvements over baseline were only seen in the FP twice-daily group (by $16.7 \mathrm{~L} / \mathrm{min}$ ), whereas mean morning PEF remained largely unchanged in the FP once-daily group (increase of $0.7 \mathrm{~L} / \mathrm{min}$ ) (Table 2) a statistically significant difference favouring FP twice daily $(\mathrm{P}<0.001)$. However, for the patients with mild asthma, the $90 \%$ confidence interval for the treatment difference, FP twice daily minus once daily $(-13.6$ to -2.8$)$ was contained in the equivalence interval. By contrast, for patients with moderate asthma, the $90 \%$ confidence interval (-20.5 to -11.1$)$ was not contained in the equivalence interval, and the criteria for declaring equivalence was not met (Table 2).

Mean evening PEF also improved over the course of each study. Overall improvements in mean evening PEF of 9.7 L/min with FP once daily compared with $13.2 \mathrm{~L} / \mathrm{min}$ with FP twice daily were observed in patients with mild asthma. In patients with moderate asthma, improvements of $4.9 \mathrm{~L} / \mathrm{min}$ with once-daily and $10.4 \mathrm{~L} / \mathrm{min}$ with twice-daily FP dosing were seen (Table 2); the improvement seen with twice-daily dosing was significantly greater $(\mathrm{P}=0.032)$.

In patients with mild asthma, diurnal variation in PEF improved with both once- and twice-daily dosing. Compared with baseline, mean diurnal variation in PEF was reduced by 
TABLE 2

Mean changes in lung function parameters from baseline to end of treatment period

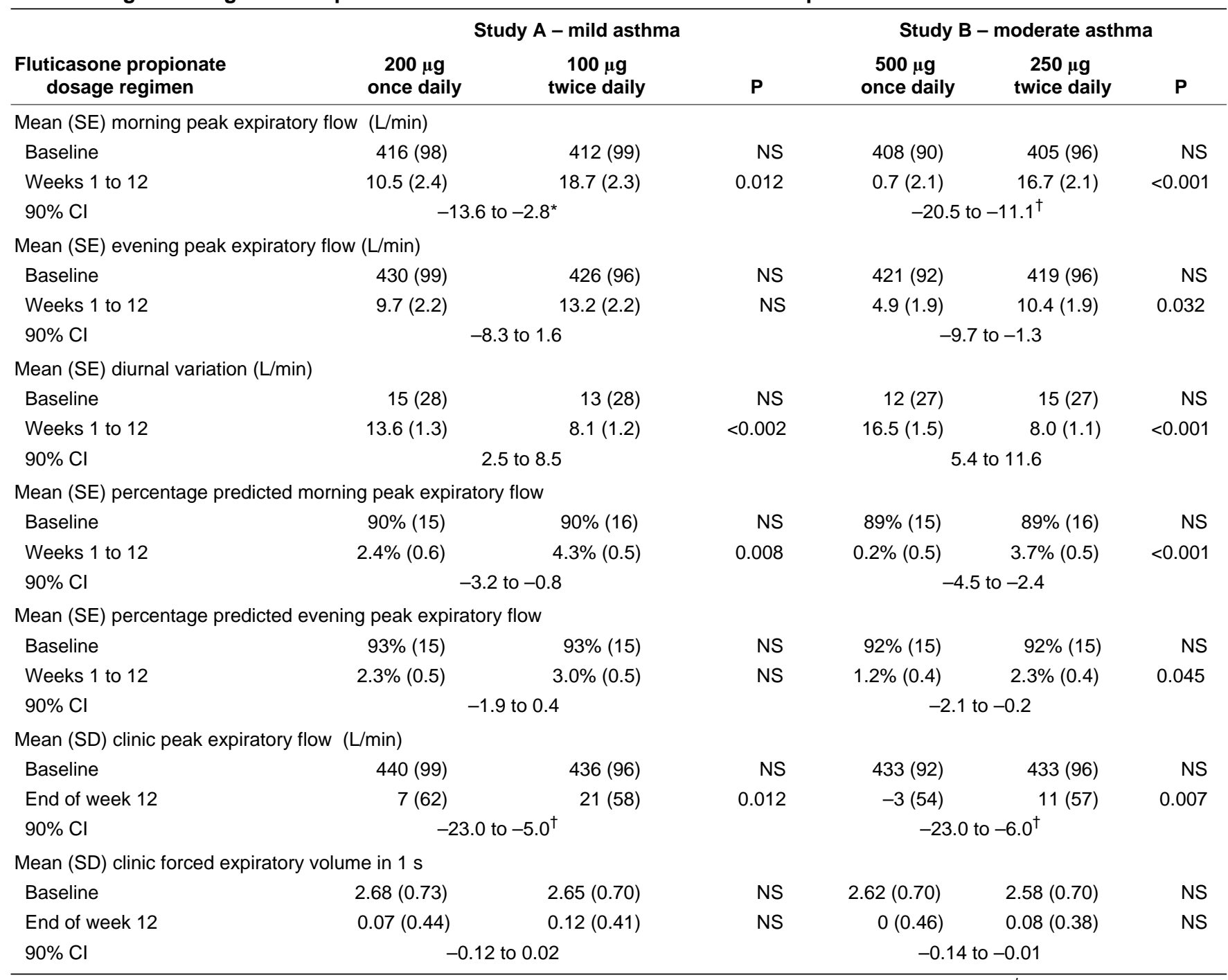

$P$ is for the difference between the two treatment groups. ${ }^{*}$ Difference contained within predefined equivalence interval; ${ }^{\dagger}$ Difference not contained within predefined equivalence interval. NS Not significant; $P>0.05$

$1.4 \mathrm{~L} / \mathrm{min}$ and $4.9 \mathrm{~L} / \mathrm{min}$, for once-daily and twice-daily dosing, respectively; the improvement was significantly greater with twice-daily dosing $(\mathrm{P}<0.002)$ (Table 2$)$. In patients with moderate asthma, those receiving once-daily dosing experienced an increase in mean diurnal variation in PEF of $4.5 \mathrm{~L} / \mathrm{min}$ compared with baseline, while those receiving twice-daily dosing experienced a reduction of $7.0 \mathrm{~L} / \mathrm{min}$. Again, the improvement was significantly greater with twice-daily dosing $(\mathrm{P}<0.001)$. Other improvements were also observed in both the mild and moderate asthma patient studies, with statistically significant differences in favour of twice-daily dosing, in mean percentage predicted morning PEF ( $\mathrm{P}=0.008$, mild asthma; $\mathrm{P}<0.001$, moderate asthma) and clinic assessments of PEF $(\mathrm{P}=0.12$, mild asthma; $\mathrm{P}=0.007$, moderate asthma) (Table 2). In patients with moderate asthma, $21 \%$ and $13 \%$ of patients with daily versus twicedaily dosing, respectively, occasionally had PEF below $85 \%$ of the run-in value more than three times in seven days.
Increases in $\mathrm{FEV}_{1}$ compared with baseline were observed in each study with both treatment groups. However, there were no significant differences in increases between treatment groups (Table 2).

Symptoms and medication needs: The patients' symptoms were well controlled before they were randomly assigned to these studies, and the use of bronchodilators was infrequent. Nevertheless, improvements were observed with both treatments in each study (Table 3). In patients with mild asthma, there were no significant differences between FP once daily and FP twice daily in daytime and night-time symptom scores or the number of days that symptom scores were less than 2 (Table 3). In patients with moderate asthma, there were significant differences in favour of FP twice daily in daytime symptom scores $(\mathrm{P}=0.025)$, night-time symptom scores $(\mathrm{P}<0.001)$ and the number of days that symptom scores were less than $2(\mathrm{P}=0.005)$ (Table 3$)$.

The improvements in asthma control during the trials 
TABLE 3

Mean changes in patient recorded daytime and night-time symptom severity from baseline to the end of the treatment period

\begin{tabular}{|c|c|c|c|c|c|c|}
\hline \multirow[b]{2}{*}{$\begin{array}{c}\text { Fluticasone propionate } \\
\text { dosage regimen }\end{array}$} & \multicolumn{3}{|c|}{ Study A - mild asthma } & \multicolumn{3}{|c|}{ Study B - moderate asthma } \\
\hline & $\begin{array}{l}200 \mu \mathrm{g} \\
\text { once daily }\end{array}$ & $\begin{array}{l}100 \mu \mathrm{g} \\
\text { twice daily }\end{array}$ & $\mathbf{P}$ & $\begin{array}{c}500 \mu \mathrm{g} \\
\text { once daily }\end{array}$ & $\begin{array}{l}250 \mu \mathrm{g} \\
\text { twice daily }\end{array}$ & $\mathbf{P}$ \\
\hline Baseline & $0.75(0.78)$ & $0.64(0.75)$ & NS & $0.87(0.85)$ & $0.82(0.81)$ & NS \\
\hline Week 12 & $-0.25(0.05)$ & $-0.23(0.05)$ & NS & $-0.08(0.05)$ & $-0.26(0.06)$ & 0.025 \\
\hline \multicolumn{7}{|c|}{ Mean percentage (SD) of days with symptom score smaller than 2} \\
\hline Week 12 & $8 \%(28)$ & $5 \%(25)$ & NS & $5 \%(23)$ & $9 \%(26)$ & 0.005 \\
\hline \multicolumn{7}{|c|}{ Mean (SD) night-time symptom scores } \\
\hline Baseline & $0.41(0.54)$ & $0.35(0.50)$ & NS & $0.37(0.53)$ & $0.39(0.53)$ & NS \\
\hline Week 12 & $-0.03(0.04)$ & $-0.09(0.03)$ & NS & $0.13(0.04)$ & $-0.07(0.04)$ & $<0.001$ \\
\hline
\end{tabular}

$P$ is for the difference between the two treatment groups. NS Not significant; $P>0.05$

TABLE 4

Mean changes in patient recorded bronchodilator use from baseline to the end of the treatment period

\begin{tabular}{|c|c|c|c|c|c|c|}
\hline \multirow[b]{2}{*}{$\begin{array}{l}\text { Fluticasone propionate } \\
\text { dosage regimen }\end{array}$} & \multicolumn{3}{|c|}{ Study A - mild asthma } & \multicolumn{3}{|c|}{ Study B - moderate asthma } \\
\hline & $\begin{array}{l}200 \mu \mathrm{g} \\
\text { once daily }\end{array}$ & $\begin{array}{c}100 \mu \mathrm{g} \\
\text { twice daily }\end{array}$ & $\mathbf{P}$ & $\begin{array}{l}500 \mu \mathrm{g} \\
\text { once daily }\end{array}$ & $\begin{array}{c}250 \mu \mathrm{g} \\
\text { twice daily }\end{array}$ & $\mathbf{P}$ \\
\hline Baseline & $0.79(1.08)$ & $0.69(0.95)$ & NS & $0.87(0.96)$ & $0.76(0.84)$ & NS \\
\hline Week 12 & $-0.23(0.06)$ & $-0.23(0.05)$ & NS & $-0.10(0.06)$ & $-0.25(0.06)$ & NS \\
\hline \multicolumn{7}{|c|}{ Mean (SD) number of times salbutamol used in the night } \\
\hline Week 12 & $-0.06(0.04)$ & $-0.17(0.04)$ & NS & $0.05(0.04)$ & $-0.11(0.04)$ & 0.003 \\
\hline
\end{tabular}

$P$ is for the difference between the two treatment groups. NS Not significant; $P>0.05$

were reflected in decreases in day- and night-time bronchodilator use (Table 4). The twice-daily patient groups demonstrated a greater decrease in both daytime and night-time bronchodilator use, although it was only significant in patients with moderate asthma for night-time use $(\mathrm{P}=0.003)$ (Table 4).

In patients with moderate asthma, the lower the baseline use of bronchodilators, the more similar the two treatments. Patients with a baseline use of three times per week or less had changes in mean morning PEF, compared with baseline, of 6.0 and $13 \mathrm{~L} / \mathrm{min}$ for once-daily and twice-daily treatments, respectively, whereas for use greater than seven times per week, the changes were -2 and $17 \mathrm{~L} / \mathrm{min}$, respectively. Adverse events and safety parameters: The adverse event profile did not differ markedly between the two treatment groups. Furthermore, the types of events reported were not unexpected for this patient population. Ear, nose and throat disorders were most often reported as adverse events by patients in both treatment groups. Approximately $31 \%$ of patients in the mild asthma study group and $54 \%$ of patients in the moderate asthma study group reported these types of events. In the patients with mild asthma, the most commonly reported events included headache $(12 \%$ and $15 \%$ for the once-daily and twice-daily groups, respectively) and upper respiratory tract infection (11\% and $10 \%$ for the once-daily and twice-daily groups, respectively). Similarly, in the study of patients with moderate asthma, most commonly reported events included headache (34\% and 33\% for the once-daily and twice-daily groups, respectively) and upper respiratory tract infections (30\% and $28 \%$ for the once-daily and twicedaily groups, respectively).

In the mild asthma study, hoarseness and/or dysphonia was the most frequently reported drug-related adverse event occurring in $2 \%$ and $5 \%$ of patients who received FP once daily and FP twice daily, respectively. In the moderate asthma study, hoarseness and/or dysphonia and throat irritation were the most frequently reported drug-related adverse events. Throat irritation was reported by $5 \%$ and $7 \%$ of patients, and hoarseness and/or dysphonia was reported by $1 \%$ and $5 \%$ of patients who received FP once daily and FP twice daily, respectively. No other drug-related events were reported by $5 \%$ or more of patients.

In both studies, the incidence of exacerbations of asthma and related events was higher in the once-daily group than in 
the twice-daily group - $13 \%$ and $5 \%$, respectively, in patients in the mild asthma study, and $12 \%$ and $10 \%$, respectively, in patients in the moderate asthma study. As expected, the majority of withdrawals were because of asthma or related events. The incidence of withdrawals was higher in the oncedaily group: 19 patients withdrew because of adverse events (16 in the once-daily group and three in the twice-daily group) in the mild asthma study and 12 patients withdrew (seven in the once-daily group and five in the twice-daily group) in the study of patients with moderate asthma.

There were no significant effects on vital signs, urinalysis, hematology or laboratory parameters, and biochemistry including serum cortisol measurements in either study. In the mild asthma study, geometric mean serum cortisol concentrations were $379 \mathrm{nmol} / \mathrm{L}$ and $383 \mathrm{nmol} / \mathrm{L}$ at baseline in the once- and twice-daily dosing groups, respectively, and $394 \mathrm{nmol} / \mathrm{L}$ and $400 \mathrm{nmol} / \mathrm{L}$, respectively, at the study end; the baseline adjusted geometric mean ratio of treatments was 1.03 for both groups. In the moderate asthma study, the baseline geometric mean values were $345 \mathrm{nmol} / \mathrm{L}$ in the once-daily group and $341 \mathrm{nmol} / \mathrm{L}$ in the twice-daily group, and at study end, the values were $346 \mathrm{nmol} / \mathrm{L}$ and $353 \mathrm{nmol} / \mathrm{L}$, respectively; the adjusted geometric mean ratio was 0.99 .

\section{DISCUSSION}

The patients in both the mild and the moderate asthma studies were relatively well controlled before being randomly assigned to treatment groups; symptom scores and use of bronchodilators were low. Patients with mild asthma had been receiving or up to $500 \mu \mathrm{g} / \mathrm{day} \mathrm{BDP}$ or BUD, and patients with moderate asthma, 400 up to $1200 \mu \mathrm{g} /$ day BDP or BUD. In both mild and moderate asthma studies, for a number of parameters, greater improvements were observed with twice-daily than with once-daily treatments. Although greater reductions in mean diurnal variation in PEF were observed with twice-daily dosing, a good level of asthma control was maintained throughout the 12-week treatment period in both the mild and moderate asthma studies, regardless of the treatment regimen (2). For the PEF changes, a good level of control has been defined as a diurnal variation in PEF of less than $10 \%$ on five of seven days (2). Accordingly, the mean diurnal variation in PEF observed in the mild asthma study averaged $3.3 \%$ and $2.1 \%$ for once- and twice-daily dosing, respectively, and in the moderate asthma study, averaged $4.2 \%$ and $2.0 \%$, respectively.

Small differences in efficacy were observed between once-daily and twice-daily administration of FP in patients with mild asthma. Within the moderate asthma group, the fewer the asthma symptoms or the lower the baseline use of bronchodilators, the more similar the efficacy of once- and twice-daily treatments of FP. These observations support those of others (10) that once-daily ICS may be more suitable for use in stable, well controlled asthma. Some patients with asthma seem to show an increase in airway inflammatory features at night, and it is possible that these patients may benefit from twice-daily dosing. Alternatively, although this remains to be confirmed by further studies, because it has been suggested that the time of administration of corticosteroids may influence their efficacy (27), the beneficial effect of corticosteroids on this nocturnal process may be optimized by late afternoon administration $(9,12,27)$.

In the present study, the once-daily dose was administered in the morning, and it is possible that the difference in efficacy between twice-daily and once-daily dosing may have been reduced if the once-daily dose had been given at the end of the day. However, the present study aimed to determine whether a single morning dose of a potent ICS was sufficient to keep asthma controlled while possibly further reducing the risk of systemic effects.

In accordance with current guidelines, it may be appropriate for the daily dose to be given just once per day during periods of good asthma control but split into two doses when features of poor control are noted, in addition to increasing the total daily dose according to the degree of loss of asthma control. Similarly, we may hypothesize that twice-daily administration may be more appropriate during periods of increased allergen exposure or at the onset of a respiratory tract infection. However, our study did not look at the effects of different modes of dosing in circumstances of loss of control of asthma; this requires further assessment. Patients with severe chronic asthma have responded better to more frequent dosing, while twice-daily FP has, however, given good results in such patients (18).

For the definition of asthma severity, in the present study patients were classified as mild or moderate according to the physician's judgment, baseline expiratory flows and medication need. Furthermore, this study did not have a steroid withdrawal phase. Although theoretically ideal, this type of study is quite demanding and complicated, and it is associated with asthma worsening, which prolongs the study. For these reasons, a steroid withdrawal phase was not not included in this study. If most patients had been overtreated, this could have reduced the possibility of observing a difference between the two treatment regimens.

Many of the previous studies comparing once-daily and twice-daily treatment regimens of ICS have offered no clear recommendation, although in clinical practice some ICS are prescribed once daily. Most of the reported studies examined small numbers of patients. In addition, these studies were often conducted over short periods varying between four and 12 weeks, which makes it difficult to predict the outcome of use in the long term (5-11). In fact, no long term studies with large patient numbers have been reported for fluticasone. In a 12 -week study of 340 patients with mild to moderate asthma, Jones et al (10) reported that $400 \mu \mathrm{g}$ BUD given once daily in the morning or evening was as effective as the same total daily dose given twice daily. However, in a 12-month study of 40 patients with moderate asthma, Weiner et al (16) reported that overall, twice-daily dosing of BUD was more effective than once-daily dosing and concluded that, for patients with worsening symptoms or for long term control of asthma, BUD twice daily is more effective than BUD once daily. Given these contradictory results with 
BUD, combined with the relatively short term results reported here with FP, further study is warranted to investigate the long term effectiveness of FP given once daily versus twice daily.

In a 12-week study, patients whose asthma was controlled on flunisolide $500 \mu \mathrm{g}$ twice daily did not show significant changes from baseline PEF values, regardless of whether they were randomly assigned to flunisolide $500 \mu \mathrm{g}$ twice daily, $1000 \mu \mathrm{g}$ once daily in the morning or $1000 \mu \mathrm{g}$ once daily in the evening (13). Similarly, patients in the 12month BUD study reported above did not show improvement over baseline PEF values (16). Patients entered into the present study were also considered to have well controlled, stable asthma. Interestingly, although patients may have been taking flunisolide, FP, BDP or BUD during the baseline period, there was evidence of a significant improvement in asthma control following 12 weeks of treatment with FP, and more so with twice-daily than with once-daily administration, suggesting that these patients still had room for improvement.

Overall, FP was well tolerated in both studies. The overall incidence and types of adverse events were similar among treatment groups in each study and were not exceptional for an ICS. However, the incidence of asthma exacerbations was greater with once-daily than with twice-daily dosing. The majority of withdrawals in both treatment groups were because of failure to control asthma exacerbations. In the current studies with once-daily dosing of FP ( 0.2 or $0.5 \mathrm{mg} /$ day $)$, there was no evidence of a difference between the dosing regimens, for the cortisol levels, which remained essentially unchanged from entry.

\section{CONCLUSIONS}

This study has demonstrated that, while twice-daily administration of FP is generally more effective than oncedaily dosing, asthma control can be maintained with oncedaily administration in most patients with mild to moderate stable asthma. Although twice-daily dosing of FP was more effective than once-daily dosing in terms of PEF, there was no significant difference between the two treatment regimens with respect to $\mathrm{FEV}_{1}$.

ACKNOWLEDGEMENTS: The authors acknowledge the help of the following investigators: Drs E Diwald, F Kashfi, A Schulheim, (Austria); Drs JL Halloy, C Mercenier, D Rozen, C Tulippe, P Van den Brande (Belgium); Drs I Ahmed, R Amyot, J Anthony, S Boucher, D Cockcroft, F Corbeil, G Cournoyer, J Day, J Del Carpio, M Drouin, A D'urzo, P Ernst, S Feanny, R Gottschalk, J Hebert, D Hummel, S Kesten, A Knight, S Lavi, JR Lemoine, M Lertzman, B Lyttle, J Mazza, S Mehra, W Moote, V Osundwa, P Patel, P Renzi, K Tse, E Varga (Canada); Drs L Andri, L Del Torre, A Dezio, G Di Giacomo, G Moscato, M Neri, M Ferrari, LI Pesco, G Scano, A Siracusa (Italy); Drs R Beasley, P Black (New Zealand); Drs J Kus, K Oklek, W Pierzchata, E Rogala, A Szcezeklik (Poland); Drs M de Abreu, R de Almeida, R d'Avila, C Chieira, F e Costa, (Portugal); Drs DJ Findlay, GS Fox, ME Johnson, BCA King, AD Mellor, RJ Muggleton, R Naik, JP O'Connell, NH Patel (United Kingdom). This research was supported by a grant from Glaxo Wellcome Inc.

\section{REFERENCES}

1. British Thoracic Society. Guidelines for management of asthma. Thorax 1993;48(Suppl):S1-S24.

2. Ernst P, FitzGerald JM, Spier S. Canadian asthma consensus conference: Summary of recommendations. Can Respir J 1996;3:89-100.

3. Postma DS, Koëter GH. Compliance with prescribed treatment in mild asthma. Eur Respir Rev 1996;6:54-6.

4. Bosley CM , Fosbury JA, Cochrane GM. The psychological factors associated with poor compliance to treatment in asthma. Eur Respir J 1995;8:899-904.

5. Mann M, Eliasson O, Patel K, ZuWallack RL. A comparison of the effects of b.i.d. and q.i.d. dosing on compliance with inhaled flunisolide. Chest 1992;101:496-9.

6. Eisen SA, Miller DK, Woodward RS, Spitanagel E, Prufybeck TR. The effect of prescribed daily dose frequency on patient medication compliance. Arch Intern Med 1990;150:1881-4.

7. Stiksa G, Glennow C. Once-daily inhalation of budesonide in the treatment of chronic asthma: a clinical comparison. Ann Allergy 1985;55:49-51.

8. McCarthy TP. The use of a once-daily inhaled glucocorticosteroid (budesonide) in the management of childhood asthma. Br J Clin Res 1993;4:55-61.

9. Gagnon M, Côté M, Milot J, Turcotte H, Boulet L-P. Comparative safety and efficacy of single or twice-daily administration of inhaled beclomethasone in moderate asthma. Chest 1994;105:1732-7.

10. Jones AH, Langdon CG, Lee PS, et al. Pulmicort Turbohaler once-daily as initial prophylactic therapy for asthma. Respir Med 1994;88:293-9.

11. Campbell LM, Gunn SD, Sweeney D. Once-daily budesonide: effective control of moderately severe asthma with $800 \mu \mathrm{g}$ once-daily inhaled via Turbohaler when compared with $400 \mu \mathrm{g}$ twice-daily.

Eur Clin Res 1995;7:1-14.
12. Pincus DJ, Szefler SJ, Ackerson LM, Martin RJ. Chronotherapy of asthma with inhaled steroids: The effect of dosage timing on drug efficacy. J Allergy Clin Immunol 1995;95:1172-8.

13. ZuWallack RL, Rosen JP, Cohen L, et al. Clinical aspects of allergic disease. The effectiveness of once-daily dosing of inhaled flunisolide in maintaining asthma control. J Allergy Clin Immunol 1997;99:278-85.

14. McGivern DW, Ward M, McFarlane JT, Smith R. Failure of once-daily inhaled corticosteroid treatment to control chronic asthma. Thorax 1984;39:933-4.

15. Munch EP, Laursen LC, Dirksen A, Weeke ER, Weeke B. Dose frequency in the treatment of asthmatics with inhaled topical steroids. Eur Respir Dis 1985;67:254-60.

16. Weiner P, Weiner M, Azgad Y. Long term clinical comparison of single versus twice-daily administration of inhaled budesonide in moderate asthma. Thorax 1995;50:1270-3.

17. Martin RJ, Cicutto LC, Ballard RD. Factors related to the nocturnal worsening of asthma. Am Rev Respir Dis 1990;141:33-8.

18. Lundbäck B, Alexander M, Day J, et al. Evaluation of fluticasone propionate $(500 \mu \mathrm{g}$ day-1) administered either as dry powder via a Diskhaler inhaler or pressurized inhaler and compared with beclomethasone dipropionate $(1000 \mu \mathrm{g}$ day-1) administered by pressurized inhaler. Respir Med 1993;87:609-20.

19. Fabbri L, Burge PS, Croonenborgh L, Warlies F, Ciaccia A, Parker C. Comparison of fluticasone propionate with beclomethasone dipropionate in moderate to severe asthma treated for one year. Thorax 1993;48:817-23.

20. Holliday SM, Faulds D, Sorkin EM. Inhaled fluticasone propionate, a review of its pharmacodynamic and pharmacokinetic properties, and therapeutic use in asthma. Drugs 1994;47:318-31.

21. Langdon CG, Capsey LJ, and the UK study group. Fluticasone propionate and budesonide in adult asthmatics: a comparison using dry-powder inhaler devices. Br J Clin Res 1994;5:85-99. 
22. Langdon CG, Thompson J on behalf of a UK study group. A multicentre study to compare the efficacy and safety of inhaled fluticasone propionate and budesonide via metered-dose inhalers in adults with mild-to-moderate asthma. Br J Clin Res 1994;5:73-84.

23. Leblanc P, Mink S, Keistinen T, Saarelainer PA, Ringdal N, Payne SL. A comparison of fluticasone propionate $200 \mu \mathrm{g} /$ day with beclomethasone dipropionate $400 \mu \mathrm{g} / \mathrm{day}$ in adult asthma. Allergy 1994;49:380-5.

24. Ayres JG, Bateman ED, Lundbäck B, Harris TAJ on behalf of an International Study Group. High dose fluticasone propionate, $1 \mathrm{mg}$ daily, versus fluticasone propionate, $2 \mathrm{mg}$ daily, or budesonide, $1.6 \mathrm{mg}$ daily, in patients with chronic severe asthma. Eur Respir J 1995;8:579-86.

25. Johnson M. Pharmacodynamics and pharmacokinetics of inhaled glucocorticoids. J Allergy Clin Immunol 1996;97:169-76.

26. US Department of Health and Human Services. International Consensus Report on Diagnosis and Treatment of Asthma. National Heart, Lung and Blood Institute. Bethesda: National Institutes of Health, 1992.

27. Reinberg A, Halberg F, Falliers CJ. Circadian timing of methylprednisolone effects in asthmatic boys. Chronobiologia 1974;1:333-47. 


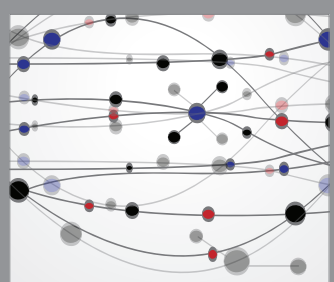

The Scientific World Journal
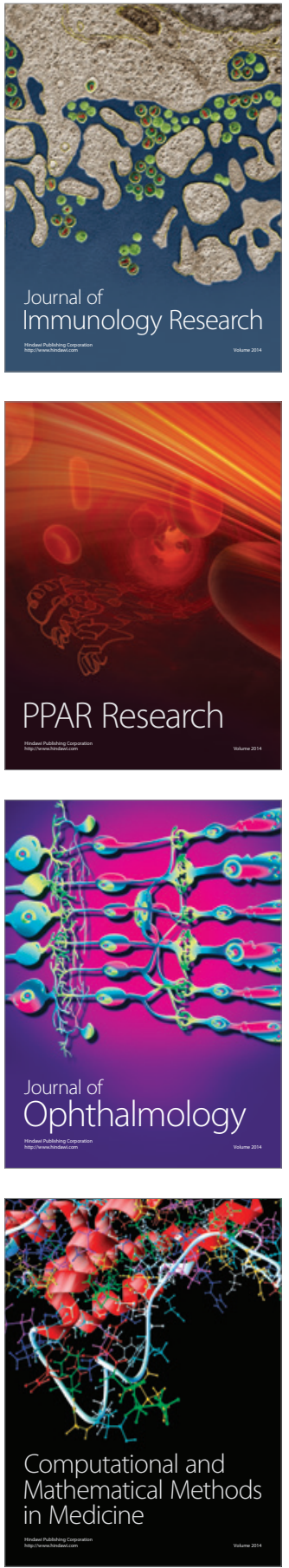

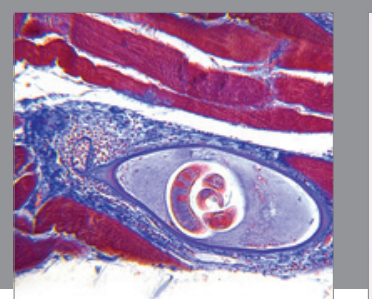

Gastroenterology Research and Practice

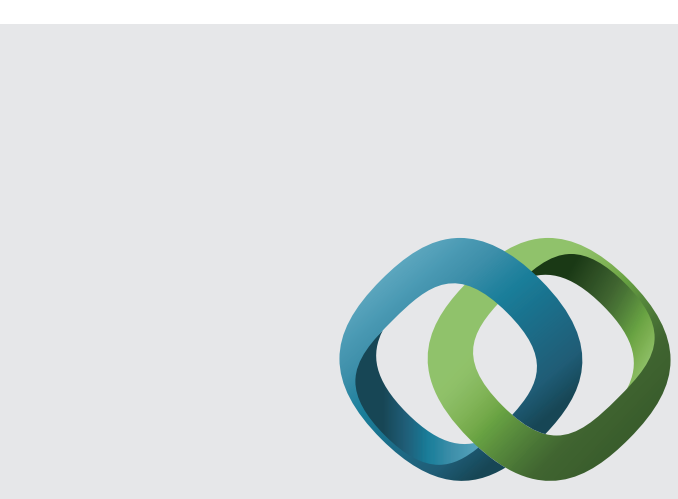

\section{Hindawi}

Submit your manuscripts at

http://www.hindawi.com
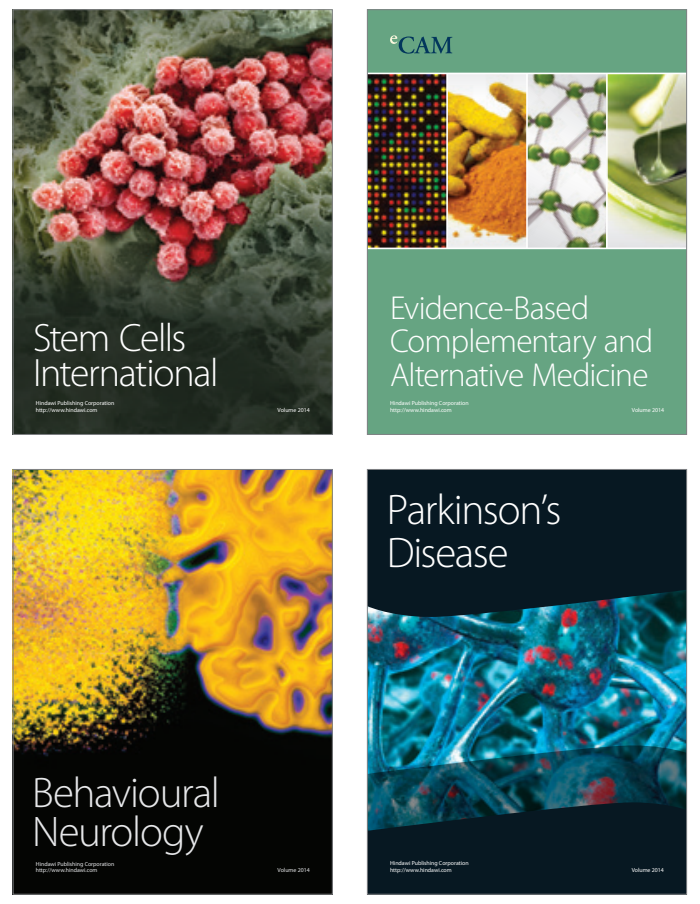
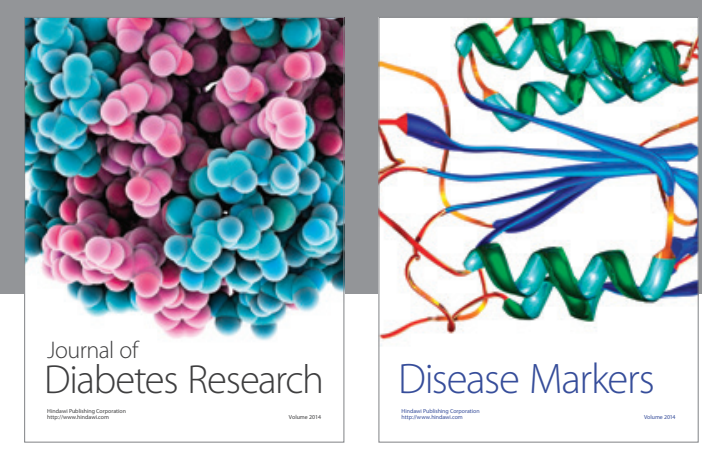

Disease Markers
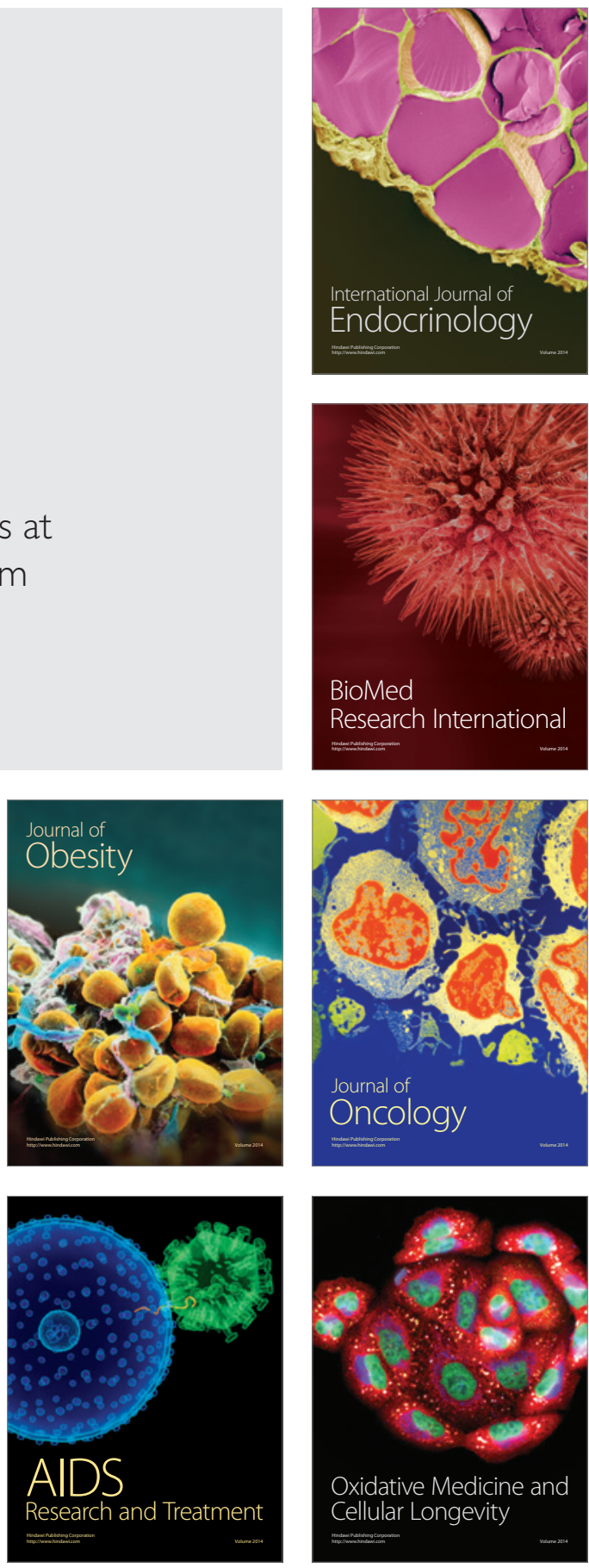